\title{
Brace treatment can change aesthetics in Adolescent Idiopathic Scoliosis (AIS) patients
}

\author{
Fabio Zaina*, Stefano Negrini and Salvatore Atanasio
}

Address: ISICO (Italian Scientific Spine Institute), Milan, Italy

* Corresponding author

from $5^{\text {th }}$ International Conference on Conservative Management of Spinal Deformities

Athens, Greece. 3-5 April 2008

Published: 15 January 2009

Scoliosis 2009, 4(Suppl I):O4I doi:|0.I|86/I748-7|6I-4-SI-O4|

This abstract is available from: http://www.scoliosisjournal.com/content/4/SI/O4 I

(C) 2009 Zaina et al; licensee BioMed Central Ltd.

\section{Background}

Aesthetics is a main goal both of conservative and surgical treatment in AIS. Previously we developed and validated a clinical scale, the Aesthetic Index (AI), to measure aesthetic impairment and changes during treatment.

\section{Aim}

To verify the efficacy of bracing on aesthetics in AIS.

\section{Study design}

Pre-post study.

\section{Population}

Thirty four consecutive patients, age $13.2 \pm 3.7$, initial Cobb Angle $30 \pm 12^{\circ}$, ATR $10 \pm 4^{\circ}$ Bunnel, 11 males.

\section{Methods}

Patients with at least 5/6 score of AI were included. All of them had a brace prescription ( 18 to $23 \mathrm{~h}$ per day). After 6 months, AI was measured again, and pre-post scores compared. The Wilcoxon test was performed. 11 of these patients already concluded treatment and definitive results are reported.

\section{Results}

At the beginning, median AI was 6 (95\% IC 5-6), after 6 months of brace AI score decreased to 2 (95\% IC 0-6) (p $<0.05$ ). In the final subgroup results, the effect of the brace was the same (from 6 to 3). After 6 months, we did not find any difference in the results according to the hours of brace wearing or to the type of exercises performed.

\section{Conclusion}

Use of a brace for just 6 months, will improve aesthetics. This is evident even in high aesthetic impact scoliosis. Completing brace treatment can guarantee the maintenance of achieved results.

\section{References}

I. Zaina F, Negrini S, Monticone M, Paroli C, Aulisa A: Repeatability of the Aesthetic Index for adolescent scoliosis idiopathic evaluation. Scoliosis 2007, 2(SuppI I):S46.

2. Negrini S, Marchini G: Efficacy of the symmetric, patient-oriented, rigid, three-dimensional, active (SPoRT) concept of bracing for scoliosis: a prospective study of the Sforzesco versus Lyon brace. Eura Medicophys 2007, 43(2): $17 \mid-81$. 